\title{
Sorbents with Immobilized Glycopeptide Antibiotics for Separating Optical Isomers by High-Performance Liquid Chromatography
}

\author{
M. A. Kuznetsov ${ }^{a}$, P. N. Nesterenko ${ }^{a}$, G. G. Vasiyarov ${ }^{a}$, and S. M. Staroverov ${ }^{a, b}$ \\ ${ }^{a}$ Faculty of Chemistry, Moscow State University, Moscow, 119899 Russia \\ e-mail:kuznetsovm@rambler.ru \\ ${ }^{b}$ Joint Stock Company BioChemMack ST, Moscow, 119899 Russia
}

Received January 19, 2006

\begin{abstract}
Chiral sorbents for HPLC separation of optical isomers carrying glycopeptide antibiotics (eremomycin or its eremosaminyl aglycon, ristomycin, or vancomycin) fixed onto the surface of silica gel have been synthesized. The patterns of the retention and separation of profen isomers and their dependence on the nature of the chiral selector and the eluant composition have been studied. The sorbents were shown to be highly enantiospecific in separating the isomers of $\alpha$-amino-, $\alpha$-hydroxy-, and $\alpha$-methylphenylcarboxylic acids (profens)
\end{abstract}

DOI: $10.1134 / \mathrm{S} 0003683806060020$

The increasing attention being paid by researchers to studies in the field of stereoselective synthesis and catalysis, as well as methods of chromatographic separation of chiral phases, observed over the last decade, is due to the requirements of the World Health Organization for the optical purity of drugs. The lack of universally applicable chiral phases for separating optical isomers prompts researchers to develop new sorbents. Immobilized macrocyclic glycopeptide antibiotics (including vancomycin, teichoplanin, ristocetin $\mathrm{A}$, avoparcin, etc.) proved to serve as chiral phases for reliable HPLC separation of a wide range of drugs [1-4]. The high enantioselectivity of the sorbents belonging to this class is due to the presence of structurally diverse fragments capable of multiple-point interactions with the compounds to be separated (in both polar and nonpolar solvents). Immobilization of new antibiotics [5], chemical modifications of their structure [6], and refinement of immobilization techniques [7] offer additional possibilities for changing the enantioselectivity of sorbents belonging to this class.

It was previously shown that eremomycin (a new antibiotic manufactured in Russia), in contrast to its closest structural analogue vancomycin, exhibits high enantioselectivity in separating isomers of $\alpha$ amino acids when immobilized on silica gel [8]. A method of its immobilization was developed that increased the selectivity of the separation, thus, rendering the sorbent superior to other chiral selectors in separating isomers of $\alpha$ amino acids [9].

In this work, we sought to explore the capacity of the new eremomycin sorbent for separating enantiomers of other classes (profens) and study the effects of structural modification of eremomycin on its enantioselectivity, as compared to the known chiral selectors vancomycin and ristomycin.

\section{MATERIALS AND METHODS}

Reagents. The antibiotics were immobilized using modified silica gels: Diaspher-110-Epoxy (particle size, $6 \mu \mathrm{m}$; specific surface, $313 \mathrm{~m}^{2} / \mathrm{g}$; pore diameter, $11 \mathrm{~nm}$; carbon content, 5.2\%) and Diasorb-130-Epoxy (particle size, $6 \mu \mathrm{m}$; specific surface, $280 \mathrm{~m}^{2} / \mathrm{g}$; pore diameter, $13 \mathrm{~nm}$; carbon content, 4.8\%) manufactured by BioChemMack ST Russia. The eluants were prepared using methanol, acetic acid, and triethylamine (Fluka, Switzerland). Eremomycin and ristomycin were synthesized using a pilot plant at the Hause Institute for New Antibiotics (Russia) [10, 11]. Vancomycin was provided by the joint stock company Veropharm (Russia). The profens and amino acids were purchased from Sigma (United States).

Obtaining eremosaminyl aglycon of eremomycin [4]. Eremomycin (3 g) was dissolved in $30 \mathrm{ml}$ of dimethyl sulphoxide, and the solution was supplemented with $2 \mathrm{ml}$ of $80 \%$ sulfuric acid, after which the mixture 
was heated for $3 \mathrm{~h}$. The target product was separated chromatographically in a $2.5 \times 11.5 \mathrm{~cm}$ column packed with Diasorb-130-C16T (particle size, 63-200 $\mu \mathrm{m}$; BioChemMack ST); aqueous acetonitrile supplemented with $0.1 \%$ trifluoroacetate served as the mobile phase ( $0-25 \%$ acetonitrile gradient). The excess solvents were removed using rotary evaporation. The yield of the product was $50 \%$; its purity by HPLC was $87 \%$.

Obtaining silica gel-immobilized eremomycin $\left(\mathbf{E}-\mathrm{SiO}_{2}\right)$. Eremomycin $(2 \mathrm{~g})$ was dissolved in $50 \mathrm{ml}$ of distilled water, and the $\mathrm{pH}$ of the solution was adjusted to 8.6 by dropwise addition of $1 \mathrm{M} \mathrm{KOH}$. The solution thus obtained was mixed with $10 \mathrm{~g}$ Diaspher-110Epoxy, and the suspension was heated at $40^{\circ} \mathrm{C}$ for $14 \mathrm{~h}$ under stirring. Following the completion of the reaction, the sorbent was separated by filtration, washed (with water, methanol, and acetone, in sequence), and dried at $50^{\circ} \mathrm{C}$ for $4 \mathrm{~h}$. The data of the elemental analysis $(12.6 \% \mathrm{C}, 2.29 \% \mathrm{H}, 1.2 \% \mathrm{~N})$ corresponded to an engraftment density of $0.35 \mu \mathrm{mol} / \mathrm{m}^{2}$.

Obtaining silica gel-immobilized eremosaminyl aglycon of eremomycin $\left(\mathrm{EA}-\mathrm{SiO}_{2}\right)$, ristomycin $\left(\mathrm{R}-\mathrm{SiO}_{2}\right)$, and vancomycin $\left(\mathrm{V}-\mathrm{SiO}_{2}\right)$. An aliquot $(1 \mathrm{~g})$ of a glycopeptide antibiotic was dissolved in a mixture of $15 \mathrm{ml}$ distilled water and $5 \mathrm{ml}$ ethanol. Thereafter, the synthesis was performed as described above for E-SiO ${ }_{2}$, except that the amount of Diaspher-110-Epoxy equaled $5 \mathrm{~g}$ and Diasorb-130-Epoxy was used for the vancomycin immobilization. The engraftment densities calculated from the data of the elemental analyses

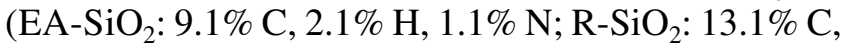
$\left.1.9 \% \mathrm{H}, 1.6 \% \mathrm{~N} ; \mathrm{V}^{-} \mathrm{SiO}_{2}: 8.3 \% \mathrm{C}, 1.6 \% \mathrm{H}, 1.8 \% \mathrm{~N}\right)$ correspond to $0.21,0.3$, and $0.2 \mu \mathrm{mol} / \mathrm{m}^{2}$.

Stainless steel $4 \times 250 \mathrm{~mm}$ columns were packed with the sorbents using a suspension technique (at $60 \mathrm{MPa}$ ). The chromatograph used in the work (Knauer, Germany) consisted of a K-1001 pump, a K-2501 spectrophotometric detector, and a dosing valve with a $20-\mu 1$ sample loop. The volume of the sample was in the range 5-20 $\mu$ l. The chromatograms were recorded and the results were processed, including the calculation of the retention $(\boldsymbol{\kappa})$, selectivity $(\boldsymbol{\alpha})$, and resolution $\left(\boldsymbol{R}_{s}\right)$ factors, using Multikhrom software (Ampersand, Russia). The idle time was determined by loading the column with a toluene solution in methanol and eluting it with methanol (photometric detection was performed at $210 \mathrm{~nm}$ ).

\section{RESULTS AND DISCUSSION}

Figure 1 presents the chemical structures of the immobilized chiral selectors, which show that each selector contains 18-38 chiral centers. It is also clear from the figure that the selectors differ in the number and type of functional groups capable of participating in chiral recognition of isomers. This variability makes it difficult to understand the mechanism whereby enantiomers are separated by macrocyclic glycopeptide antibiotics, in spite of the abundant reports on the subject. For example, sorbents containing teichoplanin, its aglycon, or ristomycin A (ristocetin) are highly selective in separating the isomers of $\alpha$ amino acids, whereas immobilized vancomycin fails to exhibit appreciable enantioselectivity [1].

We were able to previously demonstrate that a sorbent engrafted with eremomycin (the closest structural analog of vancomycin) exhibited unexpectedly high selectivity in separating enantiomers of $\alpha$ amino acids $[8,9]$. It is conceivable that the selectivity of eremomycin is due to its differences from vancomycin, such as the absence of a chlorine atom in the aromatic fragment and the presence of an additional aminoglucoside in the carbohydrate portion of the molecule [10]. Moreover, the carbohydrate residue of eremosamine is stereochemically different from that of vancosamine in the configuration of the $\mathrm{C} 4$ atom [11].

Studies of sorbents containing surface-fixed eremomycin analogues are of interest for obtaining an insight into the mechanism of chiral recognition of $\alpha$ amino acids by the eremomycin-engrafted sorbent. In this work, we obtained eremosaminyl aglycon of eremomycin (by eremomycin hydrolysis) and synthesized a chiral sorbent containing this compound $\left(\mathrm{EA}-\mathrm{SiO}_{2}\right)$. As shown in Table 1, the absence of eremosamine in the chiral selector increases its enantioselectivity for $\alpha$ amino acids with aliphatic side chains; however, the separation of isomers of aromatic amino acids is negligible. Eremosamine likely plays and important part in the chiral recognition of enantiomers of aromatic amino acids, possibly by virtue of creating ancillary steric effects.

The new chiral phases $\mathrm{E}-\mathrm{SiO}_{2}$ and $\mathrm{EA}-\mathrm{SiO}_{2}$ are not limited to separating solely optical isomers of $\alpha$ amino acids. Table 1 contains an example of separation of enantiomers of an $\alpha$ hydroxyacid (lactic acid), whereas Table 2 and Figs. 2 and 3 show the results of separation of isomers of profens ( $\alpha$ methyl-substituted acids).

Data from the literature indicate that chiral phases with engrafted macrocyclic antibiotics show promise in the separation of profens, which exhibit anti-inflammatory effects [12-15]. The therapeutic activity, however, resides in only one profen enantiomer, hence, the need for separation and determination of profens. Separation of racemic profens was studied using two types of eluants: (1) aqueous methanol (reversedphase HPLC; RP-HPLC) and (2) 100\% methanol sup- 


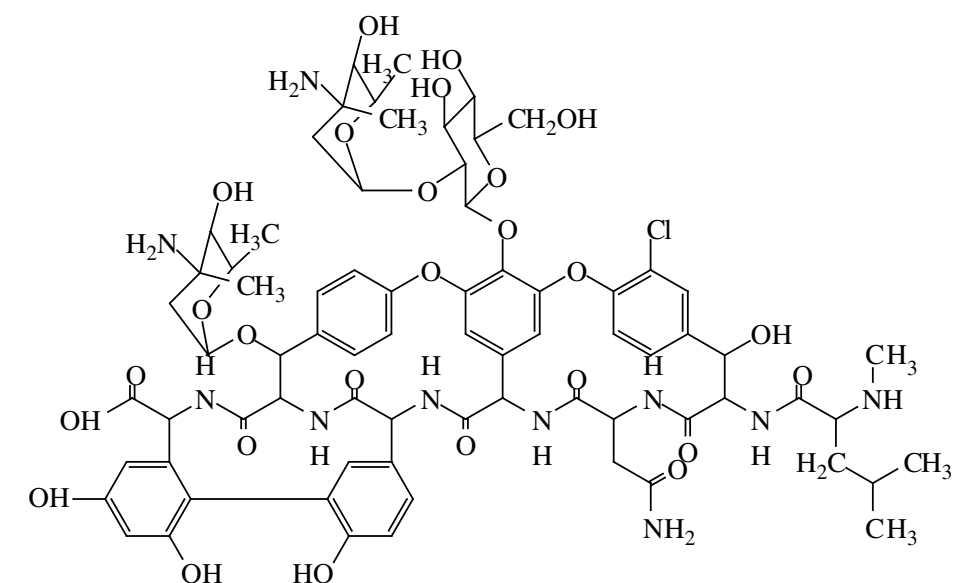

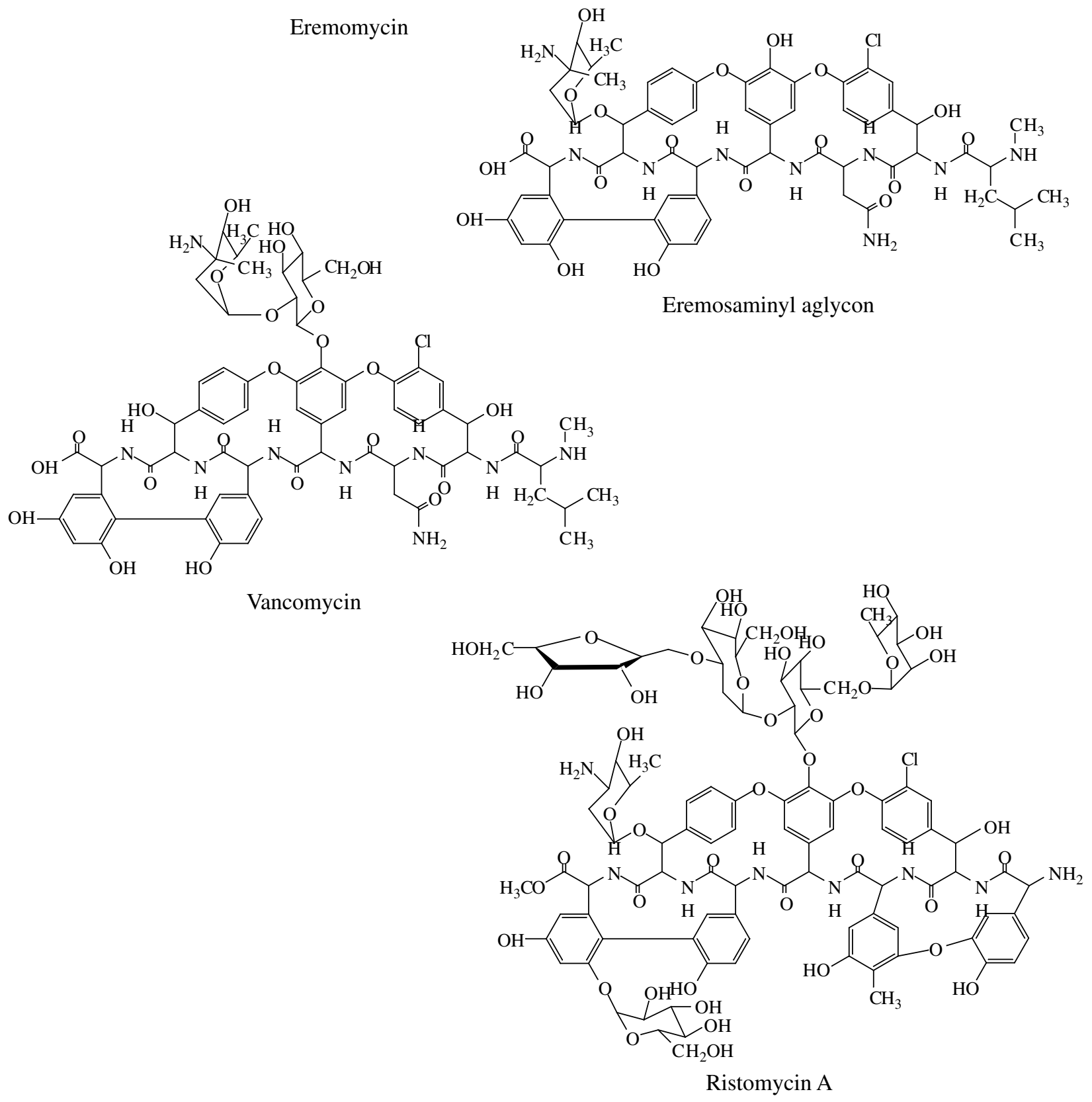

Fig. 1. Structural formulae of immobilized chiral selectors. 
Table 1. Values of the enantioselectivity $(\alpha)$ and resolution $\left(R_{S}\right)$ of columns packed with immobilized eremomycin or its aglycon in separating enantiomers of $\alpha$ amino acids (eluant, methanol-water $50: 50$ )

\begin{tabular}{|c|c|c|c|c|}
\hline \multirow{2}{*}{$\alpha$ Amino acid } & \multicolumn{2}{|c|}{$\mathrm{E}-\mathrm{SiO}_{2}$} & \multicolumn{2}{|c|}{$\mathrm{EA}-\mathrm{SiO}_{2}$} \\
\hline & $\alpha$ & $R_{s}$ & $\alpha$ & $R_{s}$ \\
\hline Alanine & 2.37 & 2.94 & 2.78 & 2.95 \\
\hline Valine & 3.35 & 4.09 & 5.89 & 4.58 \\
\hline Leucine & 2.54 & 3.64 & 3.48 & 5.20 \\
\hline Norvaline & 2.65 & 3.76 & 4.50 & 6.34 \\
\hline Methionine & 2.23 & 4.19 & 3.23 & 5.20 \\
\hline Proline & 7.94 & 7.75 & 5.63 & 4.40 \\
\hline Phenylalanine & 3.98 & 6.05 & 1 & 0 \\
\hline Tyrosine & 5.05 & 9.91 & 1 & 0 \\
\hline 3,4-dihydroxyphenylalanine & 4.28 & 10.03 & 1.16 & 0.62 \\
\hline Lactic acid* & 2.11 & 5.76 & 2.69 & 4.31 \\
\hline
\end{tabular}

* Eluant, $\mathrm{CH}_{3} \mathrm{OH}-0.1 \mathrm{M} \mathrm{NaH}_{2} \mathrm{PO}_{4}(1: 4)$.

plemented with triethylamine and acetic acid (polar ionic HPLC; PI-HPLC) [2].

Analysis of the results obtained indicates that optimum separation of profens is achieved by using eremomycin-engrafted silica gel. The selectivity and high resolution were achieved in both variants (RP-HPLC and PI-HPLC). For all the profens except phenoprofen, the values of $R_{s}$ achieved under optimum conditions exceeded 1.5, which ensured isomer separation down to the baseline. For phenoprofen, the maximum $R_{s}$ value equaled 1.42. As a rule, the RP-HPLC setting showed higher values of selectivity and resolution for all the sorbents; however, the peaks were wider than in the PI-HPLC setting (Table 2 and Fig. 3).

Reversed-phase setting. The retention of profens did not correspond to their lipophilicity, which indicated that, in aqueous methanol, the effects of additional, specific interactions with macrocyclic glycopeptide antibiotics were considerable. A decrease in the retention of both enantiomers, observed on increasing $\mathrm{pH}$ of the eluant, was the general pattern characteristic of RP-HPLC for all the sorbents studied. In the case of $\mathrm{R}-\mathrm{SiO}_{2}$ and $\mathrm{E}-\mathrm{SiO}_{2}$, this effect was paralleled by a decrease in the peak resolution $\left(R_{s}\right)$, although the selectivity remained virtually unchanged (Fig. 2). With EA-SiO${ }_{2}$, both $R_{s}$ and $\alpha$ (the enantioselectivity) increased with the $\mathrm{pH}$ of the eluant, even though not considerably. Of interest, this sorbent failed to separate enantiomers of indoprofen, which is likely due to the predominantly nonchiral binding of this compound to the graft, at least in aqueous methanol. On the whole, the best results of RP-HPLC separation of indoprofen and ibuprofen were achieved with $\mathrm{E}_{-} \mathrm{SiO}_{2}$ (the maximum values of $\alpha$ equaled 1.99 and 1.70), and those of ketoprofen and phenoprofen, respectively, with $\mathrm{R}-\mathrm{SiO}_{2}$ $(\alpha 1.94)$ and $\mathrm{EA}-\mathrm{SiO}_{2}(\alpha$ 1.58). Thus, the operational characteristics of our sorbents are superior to those of commercially available phases (such as Chirobiotic) [12-15]. 
Table 2. Values of the retention ( $\kappa)$, enantioselectivity $(\alpha)$, and resolution $\left(R_{s}\right)$ factors characterizing profen separation under the conditions of polar ionic (eluants 1-3) and reversed-phase (eluant 4) HPLC

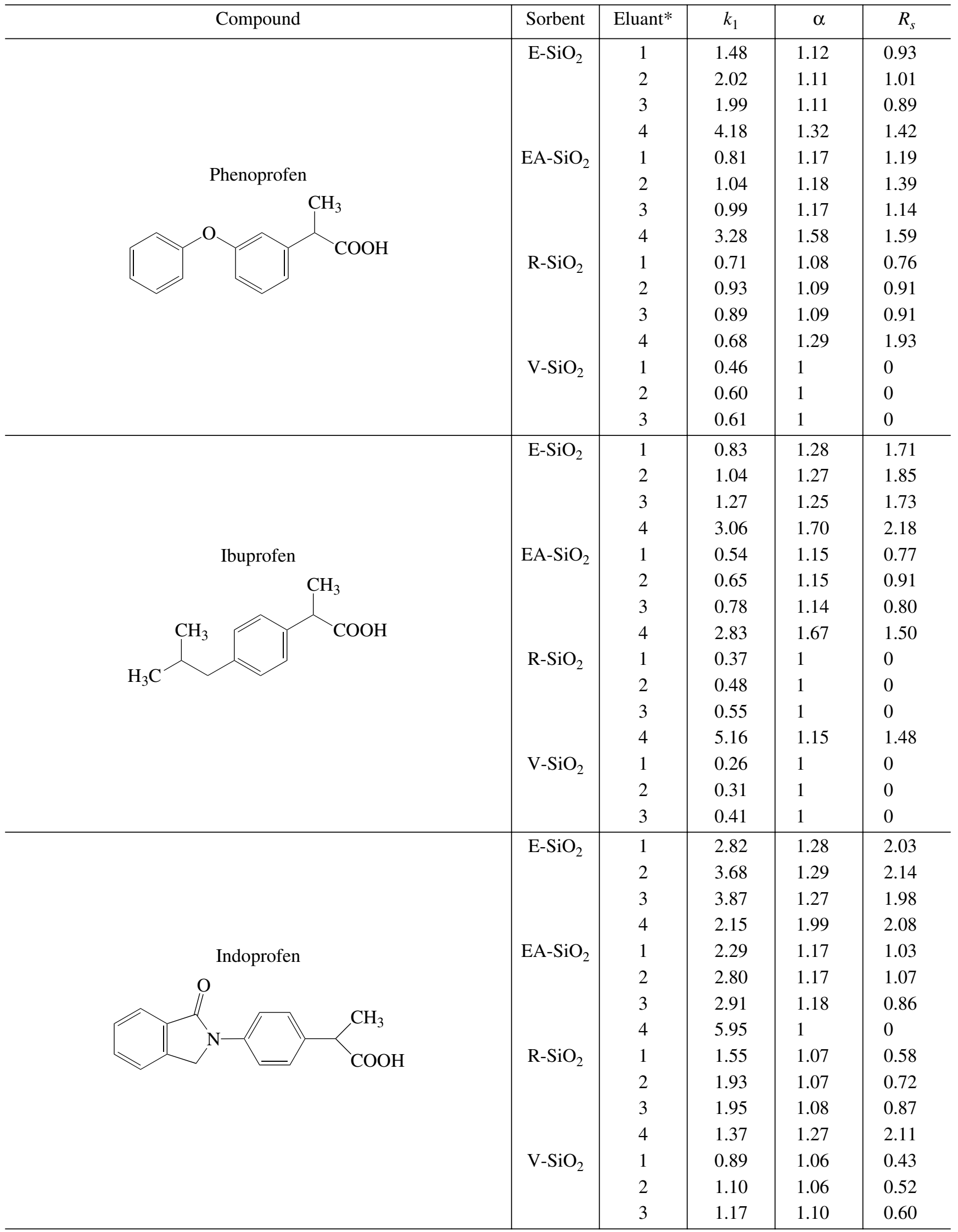


Table 2. (Contd.)

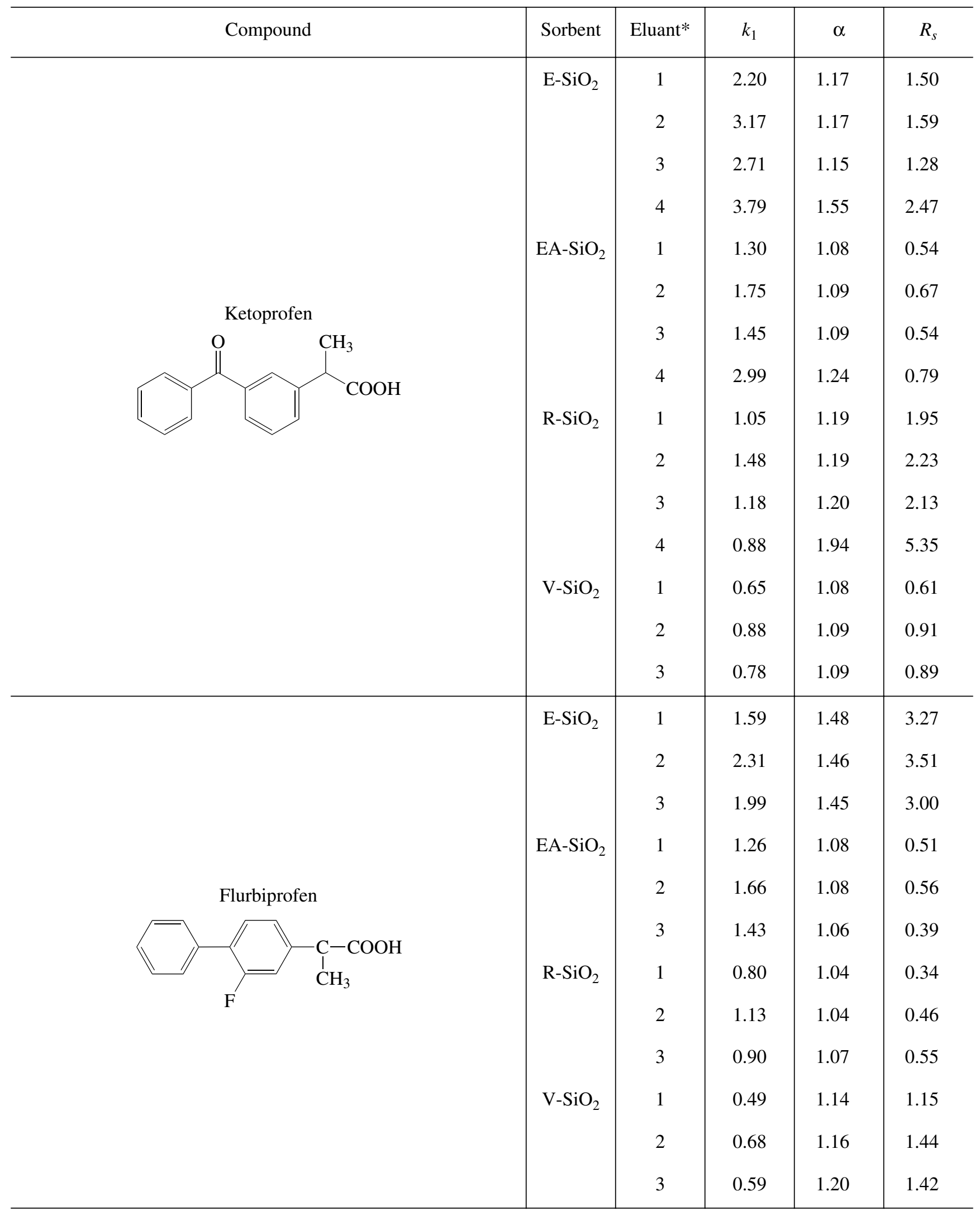

* $100 \% \mathrm{CH}_{3} \mathrm{OH}$ with supplements: (1) $0.2 \%\left(\mathrm{C}_{2} \mathrm{H}_{5}\right)_{3} \mathrm{~N}$ and $0.2 \% \mathrm{CH}_{3} \mathrm{COOH}$; (2) $0.1 \%\left(\mathrm{C}_{2} \mathrm{H}_{5}\right)_{3} \mathrm{~N}$ and $0.2 \% \mathrm{CH}_{3} \mathrm{COOH}$; and $(3) 0.2 \%$ $\left(\mathrm{C}_{2} \mathrm{H}_{5}\right)_{3} \mathrm{~N}$ and $0.1 \% \mathrm{CH}_{3} \mathrm{COOH}$. (4), $40 \% \mathrm{CH}_{3} \mathrm{OH}: 60 \% 0.1 \mathrm{M}$ phosphate buffer. 

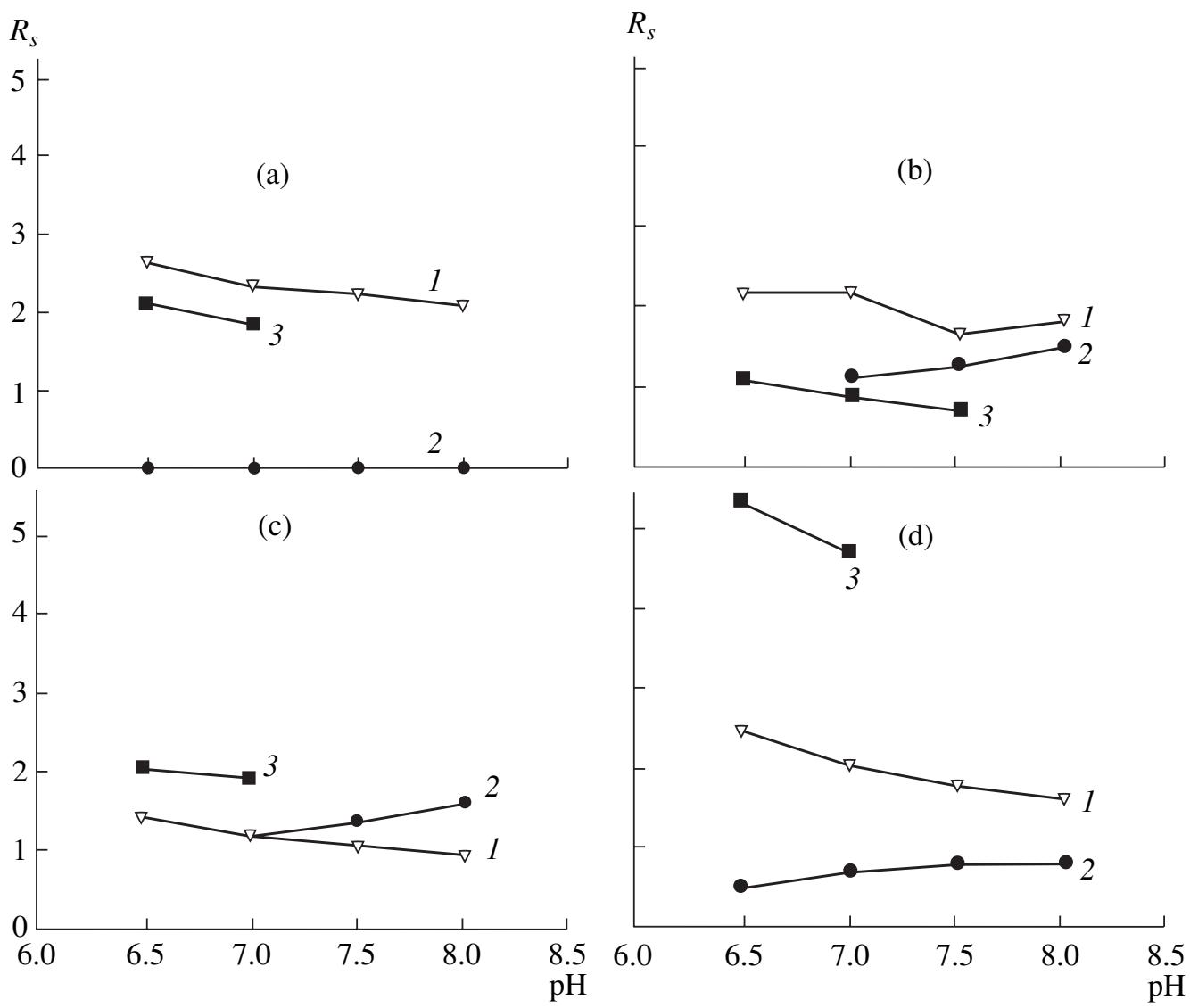

Fig. 2. pH-dependence of the resolution $\left(R_{S}\right)$ of chromatographic peaks of enantiomers of indoprofen (a), ibuprofen (b), phenoprofen (c), and ketoprofen (d) on chiral phases with silica gel carrying engrafted macrocyclic antibiotics: eremomycin (1), eremosaminyl aglycon (2), and ristomycin (3). Eluant, $40 \% \mathrm{CH}_{3} \mathrm{OH}$ and $60 \% 0.1 \mathrm{M}$ phosphate buffer.

The sorbent with immobilized vancomycin exhibited no selectivity for profens in the RP-HPLC setting; its appreciable selectivity under the conditions of PIHPLC was limited to flurbiprofen, however.

Polar-ionic setting. The use of $100 \%$ methanol supplemented with acetic acid and organic bases (e.g., triethylamine) as an eluant makes it possible to suppress the undesirable ion-exchange interactions between the sorbate and the chiral phase (noted when indoprofen enantiomers were separated on $\mathrm{EA}-\mathrm{SiO}_{2}$ under the conditions of RP-HPLC). As a result, the shape of the chromatographic peaks is improved, even though the selectivity and resolution become less pronounced (Table 2). The separation of indoprofen isomers on $\mathrm{EA}-\mathrm{SiO}_{2}$ is an exceptional case, since the value of $\alpha$ increased from 1.0 to 1.17 .

As in the case of the RP-HPLC setting, satisfactory separation of profen enantiomers under the conditions of PI-HPLC was achieved with one sorbent, $\mathrm{E}_{-} \mathrm{SiO}_{2}$. Other sorbents could be used for separating one or two sorbates, thus, showing a certain degree of specificity.
For example, the use of $\mathrm{R}-\mathrm{SiO}_{2}$ ensured the optimum separation of racemic ketoprofen, whereas $\mathrm{EA}-\mathrm{SiO}_{2}$ and $\mathrm{V}-\mathrm{SiO}_{2}$ ensured the optimum separation of racemic phenoprofen and flurbiprofen, respectively.

In conclusion, a silica gel carrying eremomycin (a surface-fixed macrocyclic glycopeptide antibiotic) exhibits high enantioselectivity in separating isomers of $\alpha$ amino and hydroxy acids, as well as enantiomers of various derivatives of 2-arylpropanoic acid (the socalled profens). The operational parameters of this sorbent are not inferior to those of commercially available analogs. With immobilized ristomycin A as an exemplary case, it is shown that the proposed method of engraftment increases the enantioselectivity of the silica gel-fixed selector for isomers of $\alpha$ methyl as well as $\alpha$ amino acids (profens).

The values of selectivity achieved under the conditions of reversed-phase chromatography suggest that the sorbents can be used for both analytical and preparative separation of profen enantiomers. 

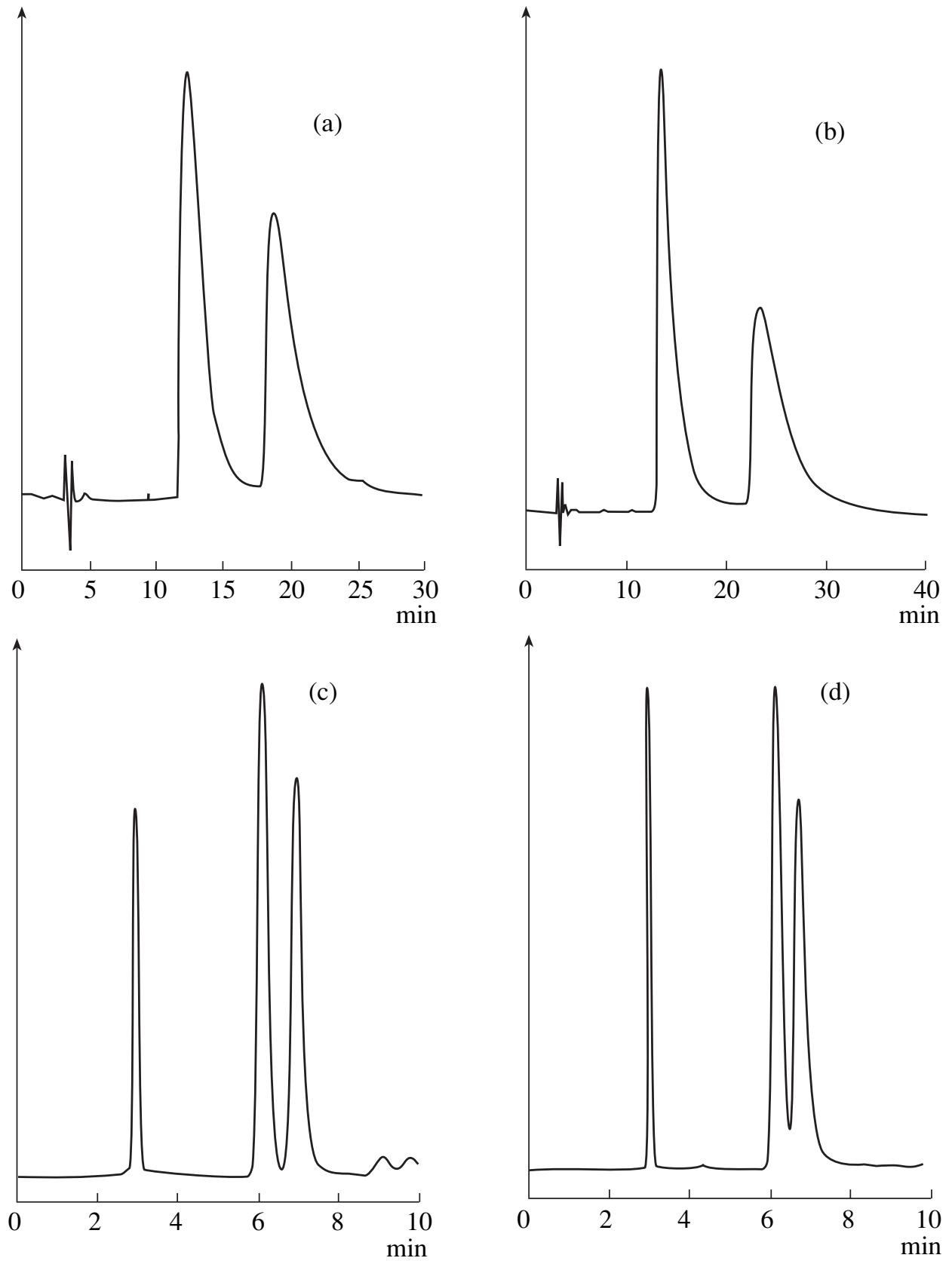

Fig. 3. Separation of enantiomers of ibuprofen (a, c), indoprofen (b), and phenoprofen (d) on sorbents with engrafted eremomycin $(\mathrm{a}-\mathrm{c})$ and eremosaminyl aglycon (d). Eluants: $40 \% \mathrm{CH}_{3} \mathrm{OH}$ and $60 \% 0.1 \mathrm{M}$ phosphate buffer, pH $6.5(\mathrm{a}, \mathrm{b})$; and $100 \%$ methanol supplemented with $0.1 \%$ triethylamine and $0.2 \%$ acetic acid (c, d). Eluant expenditure, $0.7 \mathrm{ml} / \mathrm{min}$. Detection, UV $220 \mathrm{~nm}$.

\section{ACKNOWLEDGMENTS}

This work was performed as part of project no. $02.467 / 11 / 3004$ supported by the Russian Federal Agency for Science and Innovations.

\section{REFERENCES}

1. Armstrong, D.W., Tang, Y., Chen, S., Zhou, Y., Bagwill, C., and Chen, J.R., Anal. Chem., 1994, vol. 66, pp. 1473-1484.

APPLIED BIOCHEMISTRY AND MICROBIOLOGY
2. Armstrong, D.W., Liu, Y., and Ekborg-Ott, K.H., Chirality, 1995, vol. 7, pp. 474-497.

3. Ekborg-Ott, K.H., Liu, Y., and Armstrong, D.W., Chirality, 1998, vol. 10, pp. 434-483.

4. Ekborg-Ott, K.H., Kullman, J.P., Wang, X., Gahm, K., He, L., and Armstrong, D.W., Chirality, 1998, vol. 10, pp. 627-660.

5. Berthod, A., Yu, T., Kullman, J.P., Armstrong, D.W., Gasparrini, F., D'Acquarica, I., Misiti, D., and Carrotti, A., J. Chromatogr., A, 2000, vol. 897, pp. 113-129. 
6. Berthod, A., Nair, U.B., Bagwill, C., and Armstrong, D.W., Talanta, 1996, vol. 43, pp. 1767-1782.

7. D'Acquarica, I., J. Pharm. Biomed. Anal., 2000, vol. 23, pp. 3-13.

8. RF Patent No. 2255 802, 2005.

9. Staroverov, S.M., Kuznetsov, M.A., Nesterenko, P.N., Vasiarov, G.G., Katrukha, G.S., and Fedorova, G.B., J. Chromatogr., A, 2006, vol. 1108, pp. 263-267.

10. Gauze, G.F., Lomakina, N.N., Laiko, A.V., Sveshnikova, M.A., Preobrazhenskaya, M.N., Fedorova, G.B., Borisova, V.N., Tolstykh, I.V., Yurina, M.S., Pokras, L.S., Goldberg, L.E., Markova, I.V., and Stepanova, E.S., Antibiot. Med. Biotekhnol., 1987, vol. 32, pp. 571-576.
11. Gause, G.F., Brazhnikova, M.G., Lomakina, N.N., Berdnikova, T.F., Fedorova, G.B., Tokareva, N.L., Borisova, V.N., and Batta, G.Y., J. Antibiot., 1989, vol. 42, pp. 1790-1799.

12. Pehourcq, F., Jarry, C., and Bannwarth, B., Biomed. Chromatogr., 2001, vol. 15, pp. 217-222.

13. Svensson, L.A., Karlsson, K.E., Karlsson, A., and Vessman, J., Chirality, 1998, vol. 10, pp. 273-280.

14. Ekborg-Ott, K.H., Wang, X., and Armstrong, D.W., Microchem. J., 1999, vol. 62, pp. 26-49.

15. Andersson, M.E., Aslan, D., Clarke, A., Roeraade, J., and Hagman, G., J. Chromatogr., A, 2003, vol. 1005, pp. 83-101. 